\title{
Automated Car Parking System Commanded by Android Application
}

\author{
Prof. D. J. Bonde, Rohit S. Shende, Ketan S. Gaikwad, Akshay S. Kedari,Amol U. Bhokre \\ ${ }^{\#}$ Department of Computer Engineering, \\ MMIT - Lohgaon, University of Pune, Pune - India.
}

\begin{abstract}
The aim of this paper is to propose a design of an Automated Car Parking System commanded by an Android application that regulates the number of cars to be parked on designated parking area by automating the Parking and Unparking of the car with the help of Commands of an Android Application.

The study of some existing systems shows that the level of automation in them is limited only to features like Number plate extraction, Comparison based on Snapshots of parking spaces, processing of images or Mechanical lifts in case of multilevel parking. Our system aims to reduce the human intervention to the minimal by automating the process of car parking. This in turn would prove to be useful in reducing the time required for search of free parking space by manually driving through multiple slots. The automation in the car is achieved by means of feature of Path Tracing using Sensors. We, hereby, also present a mathematical representation of our system. We also hereby present the results obtained and finally, focus on the future advancements for the project.
\end{abstract}

Keywords — Automated Parking System, Android Application.

\section{INTRODUCTION}

Variety of occasions turn up when we visit various public places like Shopping malls, 5-star and 7-star hotels, multiplex cinema halls, etc. The difficulty we encounter at these places is finding the availability of parking space. Most of the times we need to traverse through multiple parking slots to find a free space for parking. The problem becomes more tedious if the parking are multi-storeyed. Thus the problem is time-consuming.

This situation calls for the need for an automated parking system that not only regulates parking in a given area but also keeps the manual intervention to a minimum.

Our proposed system presents an Autonomous car parking that regulates the number of cars that can be parked in a given space at any given time based on the parking space availability. When a car arrives at the entrance, it will be stopped at the main gate and the driver de-boards the car. Using the Android application on his Android device, the user commands the Parking Control Unit to check the Status of available Parking slots, through an SMS. On receiving this command, a search for free slot is carried out and corresponding information is provided to the user, by means of SMS.

If the availability of Parking space is confirmed, the user commands the car to get parked to the designated slot. The car traces its path to the entrance of the parking area. Here, it waits and the details required for parking of car at the proper slot are communicated to the Car Control Unit. On receiving the information, the car will further trace its path to free parking spot. On successful parking, the data on the LCD will be updated automatically.

For retrieval purpose, the user commands "Unpark", through the Android Application. On reception of this SMS, the car begins to trace back the path to the entrance, where the car driver is waiting.

Thus this system proves to be useful for the purpose of the car parking automation and thereby helps reduce the car driver's time, as the searching of the free parking space is handled by the Parking Control Unit.Page Layout

\section{LITERATURE SURVEY}

Various methods are prevalent for development of autonomous or intelligent parking systems. Study of these systems shows that these require a little or more human intervention for the functioning.

One of the intelligent systems for car parking has been proposed by making use of Image processing [1]. In this system, a brown rounded image on the parking slot is captured and processed to detect the free parking slot. The information about the currently available parking slots is displayed on the 7-segment display. Initially, the image of parking slots with brown-rounded image is taken. The image is segmented to create binary images. The noise is removed from this image and the object boundaries are traced. The image detection module determines which objects are round, by estimating each object's area and perimeter. Accordingly, the free parking space is allocated.

A vision based car parking system [2] is developed which uses two types of images (positive and negative) to detect free parking slot. In this method, the object classifier detects the required object within the input. Positive images contain the images of cars from various angles. Negative images do not contain any cars in them. The co-ordinates of parking lots specified are used as input to detect the presence of cars in the region. Haar-like features are used for feature detection. However, limitations may occur with this system with respect to the type of camera used. Also, the co-ordinate system used selects specific parking locations and thus camera has to be at a fixed location. Limited set of positive and negative images may impose limitations on the system.

Number Plate Recognition technique [3] for developing autonomous car parking system uses image processing basis to process the number plates of the vehicles. In this system, the image of the license number plate of the vehicle is acquired. It is further segmented to obtain individual characters in the number plate. Ultrasonic sensors are used to detect free-parking slots. Then the images of number 
plate are taken and analysed. Simultaneously, the current timing is noted so as to calculate the parking fees. The LCD displays 'FULL' sign to indicate that a parking slot is not available. However some limitations with the system include background colour being compulsorily black and character colour white. Also, analysis is limited to number plates with just one row.

Smart Parking system [4] designed proposed a mechanical model with an image processing facility. The car would be parked with the use of lift at multiple levels. Also, image processing is used to capture the number plate and store in database for comparison to avoid illegal car entry.

Thus, we aim to propose a car parking system that represents a fully automated model with minimum human intervention and overcome the limitations of existing systems.

\section{SYSTEM ARCHITECTURE}

The proposed system can be represented as :-

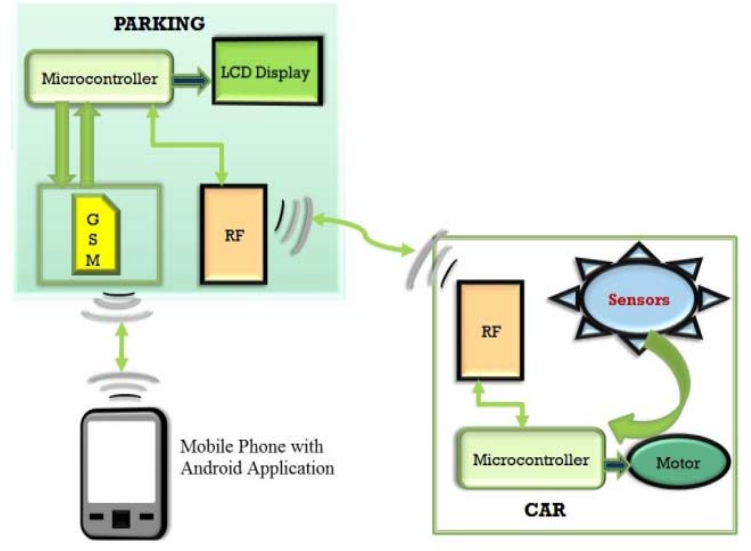

Fig.1 System Architecture

As shown in the diagram, we can get to see two subarchitectures. 1) Car Control Unit. 2) Parking Control Unit. The Parking Control Unit is commanded by the Android device having the Android application, installed. The communication between the Car and the Parking is responsible for the overall movement of the car as per data received from the Parking Unit.

The system architecture has been divided into following 4 modules -

A. Interfacing LCD with Atmega32 Microcontroller.

B. Interfacing GSM Sim900 with Atmega32

Microcontroller.

C. Interfacing RF Module (Tx, Rx) with Atmega32 Microcontroller.

\section{Android Application}

\section{Interfacing LCD with Atmega32 Microcontroller}

Interfacing between Atmega32 micro-controller and the LCD is required for displaying the status of Parking status. The LCD is set to $20 \mathrm{X} 4$ display. Depending on the status of free parking slots, the LCD counter is incremented or decremented. The data from the micro-controller is communicated using upper 4 bits of one-of the ports and the data pins of the LCD is connected to data pins D4, D5, D6, D7 of the LCD. The LCD is enabled using Enable (E) pin. Reading and writing of data to the LCD is handled using $\mathrm{R} / \mathrm{W}$ pin.

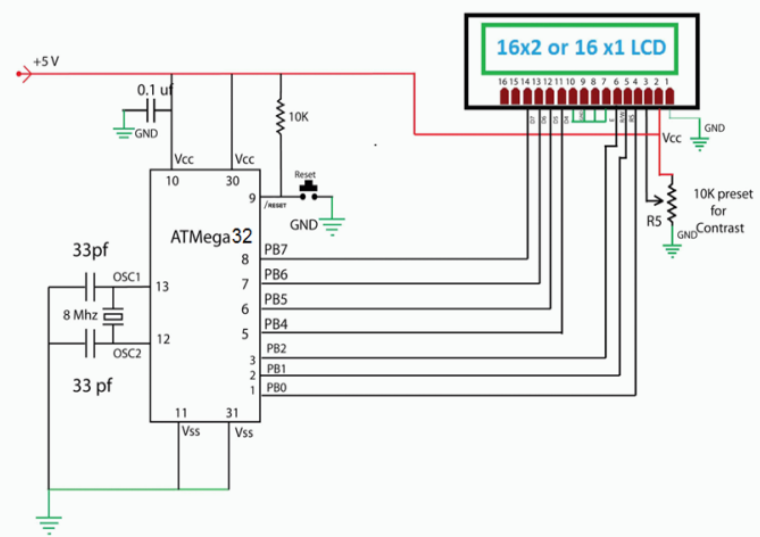

Fig 2. LCD Interface with Atmeg32

\section{Interfacing GSM Sim900 with Atmega32 Microcontroller.}

GSM stands for Global Systems for Mobile Communication. Purpose of using GSM module is the sending and receiving of SMS from Parking Control Unit. Data is transferred to and from the GSM in serially synchronized form. Before actually working on the SMS, it is important to check for the initialization and network status. The GSM has 2 pins - Tx and $\mathrm{Rx}$, which are in turn connected to the pins $\mathrm{Rx}$ and $\mathrm{Tx}$ respectively, of the Atmega32 microcontroller.

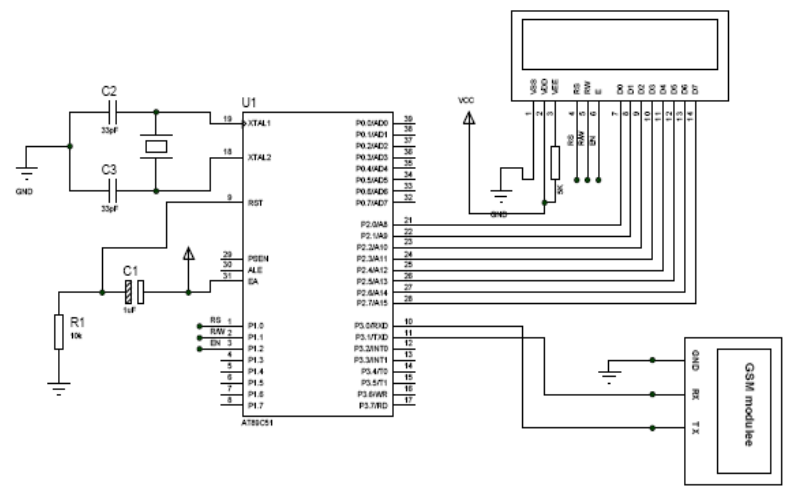

Fig 3. GSM Interfacing with Atmega32

\section{Interfacing RF Module with Atmega32 Microcontroller.}

RF Stands for Radio Frequency. RF module is a small electronic circuit to transmit and receive radio signals on a number of carrier frequencies. Purpose of interfacing RF Module with the Atmeg32 micro-controller is for the communication of data from Parking Control unit to the Car Control Unit. The data is carried using a carrier frequency of $334 \mathrm{MHz}$. 


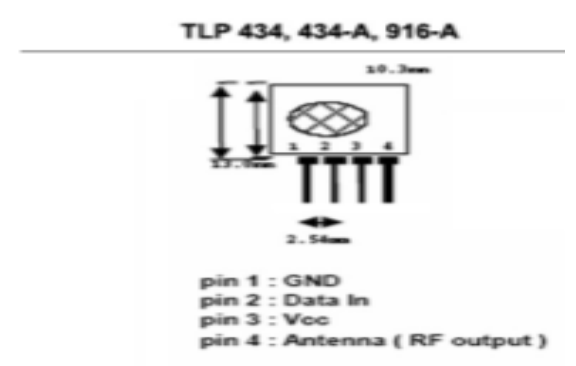

Fig 4. RF (Transmitter Module)

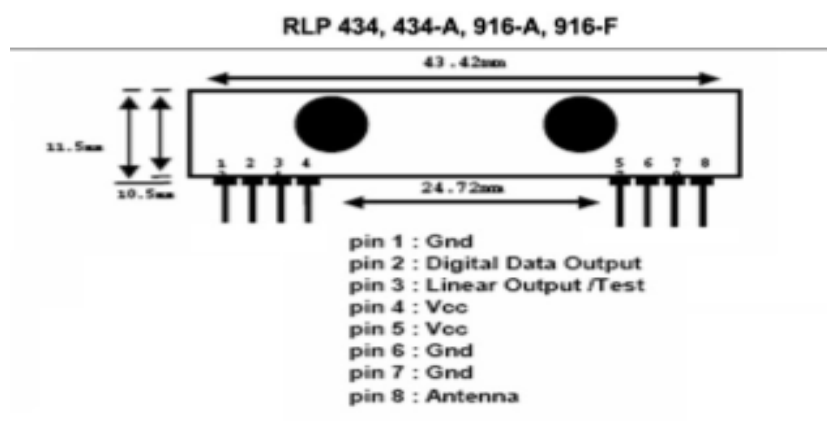

Fig 4. RF (Receiver Module)

Data is obtained from microcontroller to the buffer of RF module using the 'Data in' pin. The communication between the Tx and Rx device is of wireless type and done using the 'ANT' pin. The data stored in the buffer of the receiver is communicated to the connected microcontroller using 'Data out' pin.

\section{Android Application}

Android Application serves as a GUI for the users to send the messages through their Android Devices. It provides prompt for the user to enter the number to send SMS to and with the help of buttons provided, like, "Status" and "Get my Car" the user can command the system to do the appropriate operations. The Android Application can be easily available in the Android market which can be easily installed on the device of user.
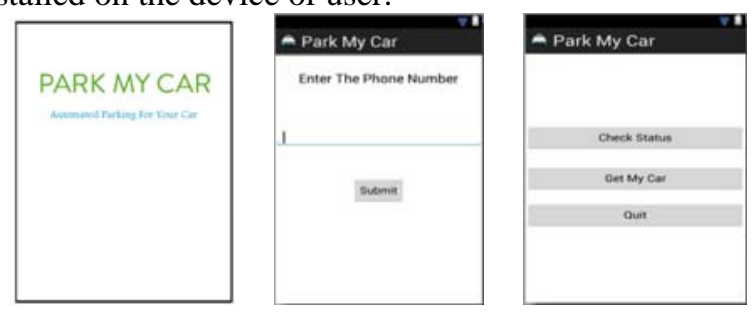

Fig 5. Android Application Snapshots

\section{Mathematical Model}

The mathematical representation of the proposed system focuses on the function for searching of free parking space and on the function to retrieve the appropriate car from the parking space.

- P- Set of Parking Areas $\mathrm{P}=\{\mathrm{P} 1, \mathrm{P} 2 \ldots \ldots, \mathrm{Pn}\}$

- I - denotes the set of slots I=\{ I1 ,I2 ,I3 ,...,In $\}$
Let -

- ES - set of Empty Slots \{I1, I2, I3,...In $\}$

- FS - set of Full Slots \{I1', I2', I3',....In'\}

Then -

$\{\mathbf{E S}, \mathbf{F S}\} \in \mathbf{I}$

- Let, $\mathrm{S}$ denote the strip numbers in the parking space - $\quad S=\{S 1, S 2, S 3, \ldots, S n\}$. Here the strips are the horizontal marks outside each parking slot, to assist the car in taking left/right turns.

- Let $\mathrm{T}$ denote the direction of Turn ( $0=$ left, $1=$ =right) - $\mathrm{T}=\{0,1\}$

- Let, C be the "Status" function which checks for the status and availability of free parking slot.

- Therefore, C $\{\mathrm{ES}, \mathrm{FS}\}$.

- Then -

\section{$\mathrm{C}: \mathbf{P * I * E S}$}

Thus 'Status' operates on Parking area consisting of various slots in it and then finding an empty slot.

- Let, G- denote "Unpark" function such that G $\{\mathrm{S}, \mathrm{T}\}$ Then-

G:S*T

This function retrieves the car based on the stored strip number(S) and the direction of turn (T).

\section{EXPERIMENTAL RESULTS}

The Automated Car Parking system has been tested and verified for the required results. The Car Parking system is able to carry out the prime functionality of searching of an empty parking slot and communicate that path to the car. The LCD module successfully shows the updations in the status of the Parking slots. The GSM module is successfully able to handle the sending and receiving of messages. The users can easily interact with the system through the GUI provided by the Android Application.

As compared to the previous systems mentioned, an automation is achieved in the parking search process and the car parking i.e. car tracing its path to the parking slot. Thus, the proposed system proves to be time-saving and an effective Parking mechanism that can be implemented commercially.

Comparative Analysis :-

\begin{tabular}{|c|c|c|c|c|c|}
\hline $\begin{array}{l}\text { Parameters } \\
\text { of Compari- } \\
\text { son }\end{array}$ & $\begin{array}{l}\text { Intelligent } \\
\text { parking } \\
\text { Detection }\end{array}$ & $\begin{array}{l}\text { Vision Based } \\
\text { Parking }\end{array}$ & $\begin{array}{l}\text { Number } \\
\text { Plate Recog- } \\
\text { nition }\end{array}$ & $\begin{array}{l}\text { Smart Park- } \\
\text { ing System }\end{array}$ & $\begin{array}{l}\text { Automated } \\
\text { Car Parking }\end{array}$ \\
\hline Automation & No & No & No & No & Yes \\
\hline $\begin{array}{l}\text { Detection of } \\
\text { Empty Slots }\end{array}$ & $\begin{array}{l}\text { Image Process- } \\
\text { ing of Brown } \\
\text { Rounded } \\
\text { Images }\end{array}$ & $\begin{array}{l}\text { Analysis of } \\
\text { Positive and } \\
\text { Negative } \\
\text { Images }\end{array}$ & $\begin{array}{l}\text { Scanning of } \\
\text { Number Plates } \\
\text { and Use of } \\
\text { Ultrasonic } \\
\text { Sensors }\end{array}$ & $\begin{array}{l}\text { Implementation } \\
\text { of Mechanical } \\
\text { Hand For } \\
\text { Parking Cars }\end{array}$ & $\begin{array}{l}\text { Use of IR Sen- } \\
\text { sors }\end{array}$ \\
\hline $\begin{array}{l}\text { Parking } \\
\text { Method }\end{array}$ & Mannual & Manual & Manual & $\begin{array}{l}\text { Mechanical } \\
\text { Lift }\end{array}$ & Path Tracing \\
\hline $\begin{array}{ll}\text { Data } & \text { Pro- } \\
\text { cessed } & \end{array}$ & $\begin{array}{l}\text { Brown } \\
\text { Rounded } \\
\text { Image }\end{array}$ & $\begin{array}{l}\text { Positive and } \\
\text { Negative } \\
\text { Images }\end{array}$ & $\begin{array}{l}\text { Number Plate } \\
\text { Images }\end{array}$ & $\begin{array}{l}\text { Level Wise Car } \\
\text { Parking }\end{array}$ & $\begin{array}{l}\text { Search of } \\
\text { First Avail- } \\
\text { able Empty } \\
\text { Parking Spot } \\
\text { Using Micro- } \\
\text { controller }\end{array}$ \\
\hline
\end{tabular}


Thus, we see that the degree of automation in our proposed system is relatively higher than it is in the existing systems.

The accuracy of the Vision based parking system was found to be $100 \%, 93.3 \%$ and $90 \%$ when detecting 1,2 and 3 number of cars respectively. The results indicate that as the number of cars increases, the accuracy of detection reduces. The reduction in accuracy was due to the type of camera used which in this project was a web camera. The camera used in this system had limited resolution and thus had a limited scope

Analysis of our proposed system :- The following table denotes the accuracy of detection of car. Each parking slot has 1 sensor for detection.

\begin{tabular}{|c|c|c|c|c|}
\hline Total Readings & 1 car & 2 cars & 3 cars & 4 cars \\
\hline \hline 10 & 10 & 10 & 10 & 10 \\
\hline
\end{tabular}

Thus, we see that the accuracy of the proposed system is maximum and remains consistent as opposed to the system it is compared with. This accuracy is the result of installation of 1 sensor per parking slot. Thus, for each slot, the accuracy of detection is $100 \%$

\section{SNAPSHOTS :-}

\section{A) Car}

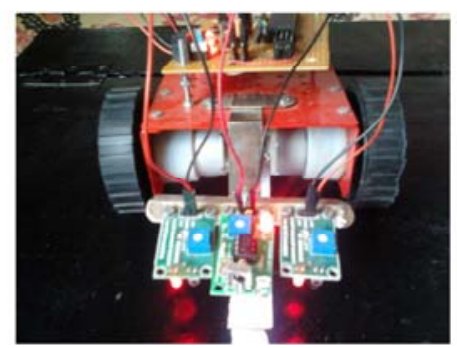

Figure 9.6: Car

B) Car Arriving at the gate

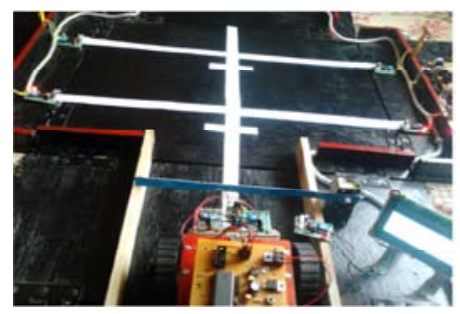

\section{C) Opening of Parking Gate}

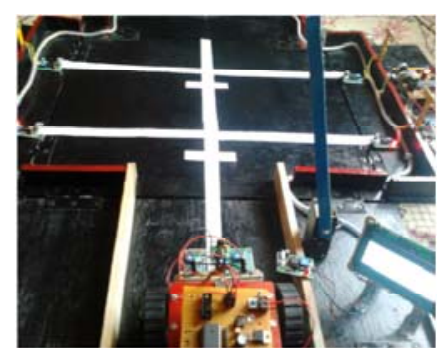

\section{D) Car Parked}

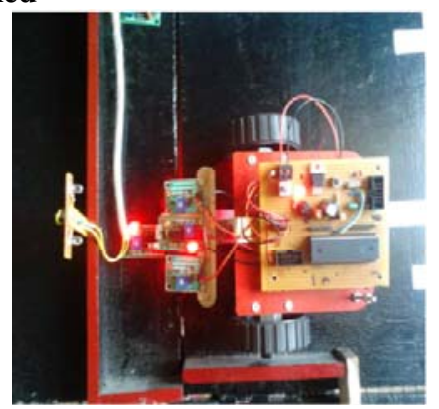

\section{Conclusion And Future Scope}

In this paper, the implementation of an Automated Car Parking system commanded by Android Application is successfully discussed. The components used for the implementation of the system provide efficient output at various stages of implementation. The interfaces established between various components provide an effective communication across the overall working of the system. Thus, the system functioning is efficient and is recommended for commercial implementation.

In future, certain changes can be incorporated as per the requirements of the organizations implementing the system. They are :-

- Search of free parking slots can be improved using Binary or Hash Search.

- System can be extended to multi-level and multiple parking areas by making potential changes in the hardware setup.

- SMS sent through Android Application can be made secure by applying encryption algorithms. Also, for security purpose, Login facility can be provided to the users.

\section{REFERENCES}

[1] R. Yusnita Fariza Norbaya Norazwinawati Bashruddin. "Intelligent parking space detection system based on image processing". International Journal of Innovation, Management and Technology, 3:232-235, 2012

[2] Hamada R.H. Al-Absi Patrick Sebastian Justin Dinesh Daniel Devaraj Yap Vooi Voon. "Vision-based automated parking system." 10th International Conference on Information Science,Signal Processing and their Applications (ISSPA 2010), pages 757-760, 2010.

[3] M.M. Rashid A.Musa M.Ataur Rehman N.Farhana A.Farhana. "Automatic parking management system and parking fee collection based on number plate recognition.” International Journal of Machine Learning and Computing, 2:93-98, 2012.

[4] M.O. Reze M.F. Ismail A.A. Rokoni M.A.R. Sarkar. "Smart parking system with image processing facility". I.J. Intelligent Systems and Applications, 3:41-47, 2012.

[5] Amba_ James Garba Adamu Murtala Zungeru, Adamu Murtala Zungeru. "Design and implementation of a short message service based remote controller". Computer Engineering and Intelligent Systems, 3:106-119, 2012. 